\title{
INDIVIDUALIDADE E CONJUGALIDADE NA RELAÇÃO DE CASAL DE ADOLESCENTES ${ }^{1}$
}

\author{
Daniela Centenaro Levandowski ${ }^{*}$ \\ Cesar Augusto Piccinini" \\ Rita de Cássia Sobreira Lopes
}

\begin{abstract}
RESUMO. O presente estudo teve por objetivo investigar as dimensões individualidade e conjugalidade na relação de casais de adolescentes, da gestação até o segundo ano de vida da criança. Participaram do estudo três casais adolescentes cujos membros tinham entre 14 e 18 anos de idade no início da coleta de dados. Foi utilizado um delineamento de estudo de caso coletivo, sendo cada casal entrevistado em quatro momentos: no terceiro trimestre de gestação, no terceiro mês, no primeiro e no segundo ano da criança. Análise de conteúdo qualitativa revelou que, de modo geral, a conjugalidade foi incrementada a partir da gravidez, ficando enfraquecida após o nascimento do bebê e sendo novamente enfatizada no segundo ano da criança.
\end{abstract}

Palavras-chave: Individualidade; conjugalidade; adolescência.

\section{INDIVIDUALITY AND CONJUGALITY IN ADOLESCENT COUPLES}

\begin{abstract}
The present study aimed to investigate the dimensions of individuality and conjugality in adolescents' romantic relationship, from pregnancy to the child's second year of life. Three adolescent couples whose members were between 14 and 18 years of age in the beginning of data collection took part in the study. A collective case study design was used. Each couple was interviewed in four moments: third quarter of pregnancy, third month, first year and second year of the child. Qualitative content analysis revealed that, in general, conjugality had increased during pregnancy, decreased after the baby's birth and was emphasized again during the child's second year.
\end{abstract}

Key words: Individuality; conjugality; adolescence.

\section{INDIVIDUALIDAD Y CONJUGALIDAD EN LA RELACIÓN DE PAREJAS ADOLESCENTES}

RESUMEN. El presente estudio tuvo por objetivo investigar las dimensiones individualidad y conjugalidad en la relación de parejas adolescentes, de la gestación hasta el segundo año de vida del hijo. Participaron del estudio tres parejas de adolescentes cuyos miembros tenían entre 14 y 18 años de edad al inicio de la colecta de datos. Fue utilizado un delineamiento de estudio de caso colectivo; cada pareja fue entrevistada en cuatro momentos: tercer trimestre de la gestación, tercer mes, primero y segundo año de vida del hijo. El análisis del contenido cualitativo reveló que, en general, la conjugalidad fue incrementada a partir del embarazo, debilitándose posteriormente al nascimiento del bebé y mostrándose nuevamente enfatizada en el segundo año de vida del hijo.

Palabras clave: Individualidad; conjugalidad; adolescencia.

Diversos autores, nos contextos nacional e internacional, têm investigado as transformações da relação de casal na transição para a parentalidade entre casais adultos (Braz, Dessen \& Silva, 2005; Curran,

1 O presente estudo deriva da Tese de Doutorado da primeira autora, realizada no Programa de Pós-Graduação em Psicologia da UFRGS, sob orientação dos demais autores.

* Doutora em Psicologia, com Pós-Doutorado em Psicologia. Docente do Departamento de Psicologia da Universidade Federal de Ciências da Saúde de Porto Alegre (UFCSPA).

\# Doutor em Psicologia, com Pós-Doutorado em Psicologia. Pesquisador do CNPq e Docente do Programa de Pós-Graduação em Psicologia da Universidade Federal do Rio Grande do Sul (UFRGS).

II Doutora em Psicologia, Pesquisadora do CNPq e Docente do Programa de Pós-Graduação em Psicologia da Universidade Federal do Rio Grande do Sul (UFRGS). 
Hazen, Jacobvitz \& Feldman, 2005; Lopes, Menezes, Santos \& Piccinini, 2006). Porém, o estudo desse mesmo fenômeno entre adolescentes não tem recebido o mesmo destaque na literatura.

Considera-se relevante o estudo desta temática pelo fato de que uma das questões psicossociais da adolescência refere-se à aquisição da intimidade, ou seja, à capacidade de estabelecer uma relação afetiva verdadeira com os pares, tanto uma amizade como um namoro (Papalia, Olds \& Feldman, 2006). Tal tarefa encontra-se relacionada à consolidação da identidade, pois, como já salientavam Aberastury (1981) e Erikson (1998), somente quando se percebe como um ser único, que necessita do outro para sua complementação, é que o adolescente poderá lançar-se a relacionamentos afetivos duradouros. De fato, questões ligadas à identidade individual podem interferir na relação de casal dos adolescentes, uma vez que somente um indivíduo minimamente separado e individualizado teria condições psíquicas de preservar seu eu dentro do nós conjugal. Por esta razão, no presente estudo investigou-se a conjugalidade e a individualidade na relação de casal de adolescentes ${ }^{2}$, pela necessidade de equilibrar, nesta relação, a identidade individual e a conjugal.

Magalhães e Féres-Carneiro (2003) definem conjugalidade como uma dimensão psicológica compartilhada da vida do casal, que possui dinâmica inconsciente, com leis e funcionamento específico, opondo-se à individualidade, que indicaria a dimensão individual presente na vida a dois. Assim, a conjugalidade faria referência à vivência compartilhada do casal em função da continuidade e estabilidade do vínculo, estando fundamentada e estruturada a partir da identidade conjugal. Dessa dimensão fariam parte aspectos inconscientes e conscientes, tais como sentimentos, emoções, fantasias, ideias, expectativas e projetos compartilhados (Féres-Carneiro \& Magalhães, 2000).

O casal seria constantemente confrontado por essas duas forças opostas, individualidade e conjugalidade. Embora os ideais contemporâneos de relacionamento valorizem mais a autonomia e a satisfação de cada parceiro do que a dependência entre eles, a constituição de um casal exige a criação de uma zona comum de interação, com a vivência de uma realidade comum, dos desejos e projetos conjugais (Féres-Carneiro, 1998).

2 No presente estudo, consideramos como casais adolescentes aqueles jovens que, em função de uma gravidez não planejada, mantiveram seu relacionamento afetivo, inclusive com coabitação.
Além disso, quanto maior a busca de autonomia, mais o casamento pode se fragilizar; ao mesmo tempo, a maior valorização da conjugalidade pode implicar ceder diante das individualidades. Neste sentido, é importante que os parceiros consigam manter um equilíbrio entre os espaços dedicados ao $\mathrm{eu} / \mathrm{tu}$ e ao nós, que será alterado em função das demandas inerentes à vivência de cada etapa do relacionamento conjugal e do ciclo vital (Falcke, Diehl \& Wagner, 2002).

Casais saudáveis conseguiriam manter o equilíbrio entre proximidade e distanciamento/diferenças individuais, comprometendo-se com a relação e sua continuidade, e, ao mesmo tempo, preservando uma fronteira para proteger a integridade e prevenir a intrusão externa e a ruptura do vínculo (Walsh, 2002). Percebe-se, então, que o equilíbrio dessas dimensões parece tanto ser conseqüência como gerar satisfação conjugal e um funcionamento psicológico adequado dos membros do casal.

Quando se considera o relacionamento afetivo entre adolescentes, pode-se supor que esse equilíbrio ficaria particularmente dificultado, tendo-se em vista a sua fase de desenvolvimento e a própria história desses relacionamentos, que tendem a ser breves e envolvem, muitas vezes, uma gravidez precoce. Neste contexto, o presente estudo teve por objetivo investigar as dimensões individualidade e conjugalidade na relação de casal de adolescentes coabitantes, que passaram pela situação de uma gestação não planejada, da gestação até o segundo ano de vida do bebê.

\section{MÉTODO}

\section{Participantes}

Participaram do estudo três casais adolescentes, cujos membros tinham entre 14 e 18 anos de idade no início da coleta de dados, sendo dois de nível socioeconômico baixo e um de nível socioeconômico médio. Todos eram residentes em Porto Alegre, RS e foram selecionados da amostra do "Estudo Longitudinal de Porto Alegre: Da Gestação à Escola" (Piccinini, Lopes, Sperb \& Tudge 1998), que recebeu aprovação do Comitê de Ética do Hospital de Clínicas de Porto Alegre (Processo n. 98293, de 30 de outubro de 1998). Dentre os 11 casais acompanhados pela primeira autora, três foram selecionados para fins do presente estudo, com base nos seguintes critérios: idade máxima inicial de 18 anos, manutenção da relação de casal, com coabitação, desde a gestação até 
o segundo ano do bebê e realização de todas as etapas de coleta de dados.

\section{Delineamento, Procedimentos e Instrumentos}

Foi utilizado um delineamento de estudo de caso coletivo (Stake, 1994) de caráter longitudinal. Cada caso foi investigado em quatro momentos: terceiro trimestre da gestação, terceiro mês, primeiro e segundo ano do bebê. A primeira autora compareceu a grupos de gestantes para explicar os objetivos e os procedimentos da pesquisa. Aquelas que desejavam participar preenchiam uma Entrevista de contato inicial (GIDEP, 1998a), que era usada para verificar os critérios de seleção dos participantes (estar esperando o primeiro filho, no terceiro trimestre da gestação e não apresentar complicações físicas durante a gestação). Aqueles casais que atendiam a esses critérios foram contatados por telefone, para se explicitarem os objetivos da pesquisa e verificar sua disponibilidade para a participação.

Após a aceitação do convite, era marcada uma entrevista na residência do casal, entre o sétimo e o oitavo mês de gestação. Nesse dia, ambos assinavam um Termo de Consentimento Livre e Esclarecido (GIDEP, 1998b) e, num segundo momento, eram solicitados a preencher a Entrevista de Dados Demográficos do Casal (GIDEP, 1998c), com o objetivo de complementar seus dados demográficos. Em um terceiro momento, eram entrevistados conjuntamente (Narrativa Conjunta do Casal sobre a sua História, GIDEP, 1998d). Na segunda fase ${ }^{3}$, aos três meses de vida do bebê, era feito um novo contato e agendada uma nova visita à residência dos participantes, que, nessa ocasião, respondiam conjuntamente a Entrevista com o Casal sobre a Experiência da Parentalidade - Terceiro Mês do Bebê (GIDEP, 1999). Na terceira fase, no primeiro ano do bebê, os participantes foram novamente contatados e foi marcada uma visita à Sala de Brinquedos do Instituto de Psicologia da UFRGS, quando foi realizada conjuntamente a Entrevista com o Casal sobre a Experiência da Parentalidade - Primeiro Ano do Bebê (GIDEP, 2000). Na quarta e última fase, no segundo ano de vida do bebê, repetiu-se o mesmo procedimento, tendo sido realizada individualmente a Entrevista com o Pai/a Mãe sobre o Desenvolvimento do Bebê - Segundo Ano do Bebê (GIDEP, 2001). Todas as entrevistas foram gravadas e transcritas literalmente para análise.

3 Em todas as fases outros instrumentos foram também aplicados, conforme descrito em Piccinini et al. (1998), mas não foram analisados no presente estudo.

\section{RESULTADOS}

A análise de conteúdo qualitativa (Bardin, 1977; Laville \& Dionne, 1999) das entrevistas foi utilizada para investigar as dimensões individualidade e conjugalidade na relação de casal de adolescentes, da gestação até o segundo ano de vida do bebê. Foram realizadas repetidas leituras das entrevistas, buscandose identificar informações que permitissem a compreensão dessas dimensões nos momentos investigados. Para tanto, foram considerados os trechos sobre a história do casal, seu relacionamento antes, durante e depois da gravidez, seus planos futuros e sua rotina (incluindo as tarefas domésticas e de cuidado do bebê). Dentro disso, o foco de análise foram os conteúdos que indicavam vivências individuais ou conjugais.

A partir da identificação desses conteúdos nas entrevistas, elaborou-se um relato sobre a relação do casal ao longo dos quatro momentos investigados. Ao final de cada relato, encontra-se um entendimento dinâmico das dimensões individualidade e conjugalidade, à luz da literatura. Após a exposição dos três casos, são discutidas as semelhanças entre eles.

\section{Caso 1: A relação de casal de Daiane e Cléber}

Daiane $^{4}$ e Cléber tinham 18 anos de idade no início do estudo. Ela era doméstica e ele, pedreiro. Seus níveies de escolaridade eram 07 e 05 anos, respectivamente, e o nível socioeconômico, baixo.

\section{Gestação}

Daiane conhecia Cléber desde criança e sempre havia sido interessada por ele. "Ficaram" juntos na festa de aniversário de uma amiga. Passaram algum tempo sem contato, pois ele "ficou" com outra menina. Quando esse relacionamento terminou, Daiane procurou-o novamente e, desde então, estavam juntos. Inicialmente Cléber não dava muita atenção para Daiane, saindo frequentemente com os amigos. Alguns meses depois, ela engravidou de um menino. Demorou a contar a novidade, por achar que não continuariam juntos; entretanto, a convivência aumentou, pois Cléber passou a morar na casa da mãe dela. Ambos consideravam essa a maior mudança do relacionamento decorrente da gestação, além da interrupção das saídas noturnas. Nesse momento, como planejavam construir uma casa própria, Cléber estava procurando emprego. Para Daiane, o fato de

4 Os nomes dos participantes foram alterados a fim de garantir a confidencialidade das identidades. 
Cléber não tê-la abandonado era o maior apoio recebido, porque "eu vejo várias gurias aqui que ficam grávidas e depois os guris nem ajudam elas, somem". Considerava que ele a estava ajudando muito e que estava sempre com ela: "Antes ele não ligava pra mim, agora eu não fico um minuto sozinha, tá sempre me cuidando". Daiane imaginava solicitar a ajuda dele com o bebê, acreditando que Cléber poderia auxiliá-la em tudo. Cléber também imaginava ajudá-la no que fosse preciso.

\section{Terceiro mês do bebê}

Nesse momento, embora já estivessem residindo na sua própria casa, ambos relataram pouco tempo para namorar, pois o bebê estava sempre com eles, até por dormir no mesmo quarto, embora em seu berço: "Quando a gente pensa que ele tá dormindo, ele já tá acordado!" (Cléber). Daiane considerava que a vida do casal estava mais corrida, mas, mesmo assim, a situação estava melhor do que imaginava. As tarefas domésticas e os cuidados do filho sempre eram divididos entre os dois, conforme a disponibilidade de cada um. Tanto Daiane solicitava a ajuda de Cléber como ele se prontificava a cuidar do filho. Não havia discordâncias quanto aos cuidados com o bebê.

\section{Primeiro ano do bebê}

Quando questionados sobre a vida conjugal, ambos falaram do filho. Cléber acrescentou que estava "normal", pois havia tempo para conversar e namorar. Daiane referiu que o menino demonstrava ciúme da proximidade do casal, "Ele empurra eu, quer ficar com ele (pai)". As saídas noturnas haviam diminuído também: "agora nem damo bola para sair" (Cléber). Como não estava trabalhando, Cléber ficava cuidando do menino e da casa. No final de semana, essas tarefas eram realizadas conjuntamente pelo casal. Daiane referiu não precisar solicitar a ajuda do companheiro, pois "ele tá sempre cuidando". Enquanto Cléber não referiu discordâncias quanto aos cuidados do bebê, ela relatou brigas eventuais pelo fato de ele levar o filho para a rua em dias frios, pois o menino tinha bronquite.

\section{Segundo ano do bebê}

Cléber sugeriu uma mudança na relação, comentando: "As crianças ficam mais espertas, aí tem que tomar cuidado no que faz. Quando nós estamos nos beijando, ele vem e tenta fazer igual às vezes, aí tem que estar maneirando". Já Daiane não percebia mudanças no relacionamento, afora o cansaço. $\mathrm{O}$ tempo do casal estava reduzido também, porque " $A$ gente não pode nem se beijar que ele já vem pra cima e ele quer beijar eu, ele fala que eu sou a namorada dele", além de o menino continuar dormindo no mesmo quarto, em uma bicama. Passavam o dia trabalhando, ficando reunidos à noite e aos finais de semana. Em função de horários de trabalho, durante a semana Daiane participava mais dos cuidados do filho, o que se invertia aos finais de semana. Cléber a auxiliava sempre que ela solicitava, sem reclamar. As discordâncias se referiam a pequenos cuidados com o filho, como a escolha da roupa. Daiane enfatizou também as brincadeiras e músicas com palavrões que Cléber ensinava para o menino.

\section{Individualidade e conjugalidade na relação de Daiane e Cléber}

No caso de Daiane e Cléber, a conjugalidade sofreu um incremento a partir e ao longo da gestação, uma vez que no namoro predominava a individualidade no relacionamento, especialmente pelo maior contato de Cléber com seus amigos. Após o nascimento do bebê, embora a conjugalidade permanecesse reforçada pela divisão de tarefas domésticas e de cuidado, ocorreu um enfraquecimento dessa dimensão no aspecto sexual e afetivo, pelas poucas oportunidades de encontro do casal, em função da presença constante do filho, do cansaço e das discordâncias quanto aos cuidados e educação. Além disso, a individualidade foi reforçada pela vivência profissional de Daiane. Já no primeiro ano da criança, apesar de as discordâncias continuarem, bem como as vivências individuais ligadas ao trabalho, ocorreu um reforço da conjugalidade, em função da retomada da atividade sexual, da manutenção da divisão de tarefas domésticas e de cuidado do filho. Por fim, no segundo ano da criança parece ter acontecido novamente um enfraquecimento da conjugalidade, embora continuasse existindo a partilha de tarefas, uma vez que os contatos afetivos e sexuais do casal estavam diminuídos e as discordâncias e vivências ocupacionais se mantinham como reforçadores da individualidade. Assim, na relação de Daiane e Cléber foram percebidas, ao longo das quatro etapas do estudo, oscilações e dificuldades no equilíbrio dessas duas dimensões. Algum espaço individual foi preservado, seja pela conservação de atividades profissionais diferentes, seja pelo contato com amigos, e para Cléber, também pela realização de atividades de cuidado e passeios somente com o filho, sem a inclusão da parceira.

\section{Caso 2: A relação de casal de Miguel e Adriane}

Adriane e Miguel tinham 17 anos de idade e 10 anos de escolaridade no início da pesquisa. Eles 
cursavam o Ensino Médio e não exerciam atividades remuneradas. O nível socioeconômico do casal era médio.

\section{Gestação}

Miguel e Adriane se conheceram e "ficaram" juntos em uma festa de aniversário do filho de um vizinho comum; mas, como Miguel namorava, por seis meses se encontraram esporadicamente. Depois que ele terminou o namoro, "foi um grude só" (Adriane); passavam todos os dias juntos. Após seis meses, ela engravidou de uma menina. Miguel não percebeu mudanças na relação desde então, enquanto ela acreditava que havia tanto melhorado como piorado: sentia-se cobrada quanto à alimentação e ao uso de medicamentos para a anemia, ao mesmo tempo em que considerava isso um cuidado do parceiro para com ela. Adriane também referiu um aumento das brigas e ciúme da atenção de Miguel para com a filha, sentindo-se uma "barriga de aluguel, porque ele pega e começa 'Ai, meu amorzinho, não sei o quê', e eu digo: 'olha, não te esquece que eu tô aqui também!'. Enquanto Miguel acreditava que o casal ficaria ainda mais unido com o nascimento da filha, Adriane tinha medo de perder a atenção dele, mas também esperava uma melhora no relacionamento, "Eu espero que a gente se ocupe um pouco com outras coisas, no caso, com ela, e o nosso relacionamento se estabilize um pouco mais". Além disso, esperava que ele fosse fiel e se afastasse dos amigos, por achar que não poderia levar o mesmo tipo de vida que as pessoas de sua idade, em função da responsabilidade assumida. Por outro lado, reconhecia o grande apoio recebido do namorado, pois solicitava sua companhia e atenção constantemente, "Ele se preocupa com as necessidades (...) ele me dá as roupas pra eu colocar (...) É ele que cuida de mim”. Imaginava solicitar seguidamente o seu apoio, acreditando que ele desejaria tomar conta de tudo. Miguel tinha a mesma expectativa.

\section{Terceiro mês do bebê}

Conforme o depoimento de Adriane, o tempo do casal estava escasso, mesmo morando juntos na casa da mãe de Miguel, pois estavam sempre com a filha. Como ambos estudavam em turnos alternados, quem estava em casa cuidava da menina. Somente à noite e aos finais de semana se encontravam. As tarefas domésticas e de cuidado eram partilhadas nesses momentos. Apesar disso Miguel não se sentia ajudado: "ela só pede e, quando eu peço, 'Ai, não posso', 'Ai, não quero', 'Ai, não dá', é sempre assim”, queixando-se ainda do jeito desorganizado de
Adriane. De fato, ela solicitava-o constantemente, recebendo todo o apoio necessário. Por outro lado, sentia-se bastante cobrada, "Ele diz que eu sou uma inútil, mas ele sempre acaba fazendo. E ele gosta assim, ele não se importa, ele assume tudo, ele pega e vai fazendo as coisas sem eu pedir”. Discordâncias foram observadas em relação à alimentação da filha e à frequência da troca de fralda.

\section{Primeiro ano do bebê}

Ambos referiram que a vida do casal estava bem corrida, em função do trabalho: "O tempo que a gente tem pra estar junto é pra comer e dormir" (Adriane). Como estavam trabalhando e estudando, apenas à noite e aos domingos se encontravam, costumando assistir a filmes ou ir à pracinha. Miguel também saía com seus amigos. As tarefas de cuidado ainda estavam sendo divididas entre eles. Adriane continuava solicitando a ajuda de Miguel, que se mostrava mais resistente, o que se tornara um motivo de discussão do casal. Ele, por sua vez, achava que ela ainda se mostrava preguiçosa em alguns momentos. Permaneciam as discordâncias quanto à escolha das roupas e à alimentação da filha. Além disso, Adriane reclamava que Miguel pegava "os bicos $e$ as mamadeiras dela e coloca[va] na própria boca”.

\section{Segundo ano do bebê}

Para Miguel, a relação "tem aquelas briguinhas de sempre, mas eu acho que faz parte. Em geral, tá melhor, eu acho que com o tempo vai se acostumando". Adriane também confirmou que as brigas haviam aumentado, porque, em função de Miguel estar desempregado, passavam mais tempo juntos. Mas, por outro lado, "ele tá grudado comigo, que antes ele não tava”. A filha seguia dormindo no quarto do casal, em um berço próximo à cama. Como passavam o dia inteiro juntos, dividiam as tarefas domésticas e de cuidado. À noite ele estudava, ficando a menina com Adriane. Permaneciam as discordâncias em relação à escolha das roupas da filha.

\section{Individualidade e conjugalidade na relação de Adriane e Miguel}

Nesse caso, a conjugalidade sofreu um grande incremento a partir do início do namoro e durante a gestação, dando indícios até de fusionalidade. Porém, no terceiro mês percebeu-se um enfraquecimento dessa dimensão, pela presença constante do bebê, pela falta de ajuda mútua nas tarefas domésticas e de cuidado e discordâncias em relação a elas, além da pequena convivência (pouco diálogo, poucas trocas afetivas e sexuais). Tal situação se manteve no primeiro ano da criança, contribuindo negativamente 
para isso, além dos fatores já citados, a retomada dos estudos e a entrada no mundo do trabalho, o que serviu para reduzir ainda mais o tempo de convivência do casal. Além disso, Miguel também reforçava o polo da individualidade devido a um maior investimento nas relações de amizade, o que Adriane, em função de dificuldades pessoais, não conseguia fazer. Por fim, no segundo ano, apesar da maior proximidade afetiva, maior apoio mútuo e tempo de convivência, que reforçavam a conjugalidade, existiam muitas discussões e a presença constante da filha e o investimento de Miguel em suas relações de amizade permaneciam, o que contribuía para o enfraquecimento dessa dimensão da relação. Assim, ao longo dos 24 meses, notou-se uma dificuldade em equilibrar essas duas dimensões da relação de casal. Algum espaço individual foi preservado por Adriane e Miguel, em função de atividades escolares e profissionais diferentes, e, no caso dele, também pelo contato com amigos. Desse modo, ele conseguiu usufruir muito mais dessas vivências do que Adriane.

\section{Caso 3: A relação de casal de Dante e Ana}

Ana e Dante eram de nível socioeconômico baixo. Ana tinha 14 anos de idade e 08 anos de escolaridade no início do estudo, enquanto Dante, 16 anos de idade e 04 de escolaridade. Ela era estudante (Ensino Fundamental) e ele, jardineiro.

\section{Gestação}

Ana e Dante se conheceram e "ficaram" juntos através de um casal de amigos que tinham em comum, em uma janta na casa desses amigos: "foi meio arranjado desde o início, meio certo pra namorar $e$ pra ficar" (Ana). Aproximadamente 20 dias depois, aos 14 anos recém-feitos, Ana engravidou de um menino. Decidiram continuar juntos em função da gravidez. Dante passou a morar na casa dos pais de Ana, tendo gostado da mudança. Ambos consideravam que a gravidez os havia unido: "antes a gente gostava um do outro, mas era mais distante, mais separado, eu pensava em mim e ele pensava nele. Agora, tudo que eu penso, eu penso nele também, e ele eu acho que é a mesma coisa”. Dante também acreditava que a relação havia melhorado pela diminuição das saídas noturnas. Referiram planos de construir uma casa própria, atrás da casa dos pais de Ana; para tanto Dante estava procurando emprego. $\mathrm{Na}$ percepção de Ana, o relacionamento mudaria após o nascimento do menino, pelo ciúme de Dante, "porque agora toda a minha atenção é pra ele e eu acho que ele vai sentir, a gente vai se distanciar um pouco, isso é provável, mas não quero que seja demais”. Segundo
Ana, Dante estava sempre com ela, dando-lhe todo o apoio que precisava, especialmente em termos afetivos, o que ele confirmou. Ela imaginava solicitar a sua ajuda sempre que necessário e ele pretendia ajudá-la sempre.

\section{Terceiro mês}

Nessa ocasião, Dante disse ser raro o tempo do casal: somente quando os pais de Ana saíam com o neto. Comentou que quase se separaram, em função do ciúme dela e das discordâncias quanto ao uso do dinheiro. Além disso, porque "enjoa, muito tempo, assim, a gente faz um ano e pouco que tá junto. Aí a gente queria dar um tempo, eu fui lá pro meu pai, fiquei uns dias lá... aí voltei”. Para ele, a maior dificuldade era a falta de emprego. Ana comentou que a maior mudança no relacionamento era o fato de terem que pensar primeiro no filho, "comprar as coisas pra ele”. Dante trabalhava de dia, enquanto Ana cuidava da casa e do filho. Quando ele estava em casa, dividiam as tarefas de cuidado. À noite e aos domingos ficavam juntos, costumando passear ou descansar. Sempre que precisava, Ana solicitava o apoio de Dante, que a auxiliava. Não referiram discordâncias quanto aos cuidados com o menino.

\section{Primeiro ano do bebê}

Ana comentou que a vida deles estava bem corrida, diferentemente do que ela imaginava: “Eu e o pai dele, depois que ele nasceu, nós não saímos mais, não por não querer, mas a gente pensa assim: 'Ah, não vamos deixar o $R$. [filho] em casa”. Ao mesmo tempo, como Dante estava desempregado, a convivência deles havia aumentado, assim como as brigas: "tem vezes que a gente discute por nada... ele fica preocupado com alguma coisa e desconta em mim, sabe, e eu não acho certo”. Em função disso, ainda não haviam construído a casa. Como durante a semana Dante passava o dia procurando emprego, Ana cuidava do filho e da casa. À noite, ambos estudavam. Aos finais de semana, a convivência era maior e costumavam passear e brincar com o filho. A mãe dela a auxiliava nos cuidados e tarefas domésticas, pois Dante não se responsabilizava por isso. Por vezes Ana solicitava a ajuda dele, outras vezes ele tomava a iniciativa, mas em vários momentos se incomodava e reclamava quando ela pedia a sua ajuda. As discordâncias se restringiam apenas à escolha das roupas do filho.

\section{Segundo ano do bebê}

Ana acreditava que a relação do casal estava boa: "Dentro do possível eu acho que a gente tá mais 
unido, claro, a gente briga mais, mas acho que pela nossa idade, a gente estar junto há quase três anos já é uma glória, com filho e tudo". Dante também comentou que o relacionamento estava bom,: "Não tenho queixa, a gente tem mais carinho um com o outro (...) pra mim mudou muita coisa desde que eu conheci ela... me deu sentido na vida". Conseguiam namorar quando o filho adormecia, apesar de ele ainda dormir no mesmo quarto. Durante a semana, Dante trabalhava e Ana ficava tomando conta da casa e do filho. Aos finais de semana, ele a auxiliava nas tarefas de cuidado e costumavam passear com o filho. Eventualmente o deixavam com os pais de Ana para saírem sozinhos. A única discordância do casal era o fato de Dante às vezes não querer brincar com o menino.

\section{Individualidade e conjugalidade na relação de Ana e Dante}

Tomando por base o material apresentado acerca da relação desse casal, pode-se perceber que antes da gestação houve pouco espaço e tempo para a construção da intimidade e o reforço da conjugalidade, em função da ocorrência precoce da gravidez. Mas, a partir disso, pelo fato de passarem a morar juntos e conviver mais, bem como terem que preparar o espaço do bebê, parece ter havido um maior conhecimento mútuo, que levou ao incremento da conjugalidade. Não obstante, no terceiro mês percebeu-se um enfraquecimento dessa dimensão, pela falta de espaço físico e tempo para a construção da intimidade, por discordâncias em relação ao dinheiro e pouco aproveitamento do tempo conjunto para as trocas afetivas. As vivências individualizadas de Dante se limitavam ao trabalho e as de Ana, à permanência em casa apenas com o filho. O enfraquecimento da conjugalidade se manteve no primeiro ano, pois, apesar da maior convivência, decorrente do desemprego de Dante, aumentaram as brigas e discordâncias, além de continuar a não haver espaço e momentos de interação para a construção da intimidade. Além disso, ambos estavam tendo vivências individualizadas ligadas à escolarização. Apesar disso, de modo contrário, no segundo ano verificou-se um forte incremento da conjugalidade, com uma reaproximação afetiva e sexual do casal, a partir do cultivo de um tempo comum, da diminuição das brigas e discordâncias e do aumento da colaboração nas tarefas de cuidado. As vivências individualizadas também continuaram acontecendo para ambos. De todo modo, percebeu-se, ao longo dos 24 meses, certa dificuldade em equilibrar as dimensões individualidade e conjugalidade. Algum espaço individual foi preservado, em função de atividades familiares e escolares diferenciadas e, no caso de Dante, também pela atividade profissional.

\section{DISCUSSÃO}

Examinando-se conjuntamente os relatos dos três casais adolescentes investigados, observou-se tanto dificuldade de equilíbrio quanto uma oscilação das dimensões individualidade e conjugalidade na relação, ora predominando a primeira, ora a segunda. Dados semelhantes foram encontrados por Dias (2000) e Féres-Carneiro (2001) entre casais adultos da classe média carioca.

Como afirmam Falcke et al. (2002), o equilíbrio entre os espaços dedicados ao eu e ao nós sofre alterações em função das demandas inerentes a cada etapa do relacionamento e do ciclo vital percorrida. Entre os casais do presente estudo, a partir da notícia da gravidez e durante este período, a conjugalidade ficou destacada, em função da preparação das condições materiais e psicológicas para a chegada do bebê. Nesse sentido, Colarusso (1990) afirma que o vínculo objetal em direção ao parceiro fica mais fortalecido a partir da parentalidade, devido ao exercício de papéis complementares, para garantir a sobrevivência do bebê.

No entanto, no terceiro mês de vida ficou evidente o enfraquecimento da conjugalidade, por brigas, diminuição do contato afetivo e sexual (em função da presença do filho) ou maior investimento emocional na relação com a criança, que passou a suprir as necessidades afetivas antes direcionadas à relação de casal. Tais achados corroboram as ideias de Costa e Katz (1992) de que o nascimento do primeiro filho rompe a simbiose conjugal estabelecida antes da gravidez. Esse movimento de limitação da conjugalidade e de reformulação do espaço conjugal a partir da chegada do primeiro filho foi observado em casais adultos gaúchos (Correa, 2001). Somente no segundo ano a conjugalidade parece ter sido novamente fortalecida nos casais do presente estudo, momento em que a criança passou a ter maior independência em relação aos pais (Papalia et al., 2006).

Somado a isso, pôde-se verificar, entre os casais investigados, que a frágil intimidade estabelecida durante o namoro parece ter contribuído para o enfraquecimento da conjugalidade na transição para a parentalidade. Pensa-se que isso tenha acontecido em função do pequeno tempo de relacionamento antes da gestação. Mesmo a coabitação não parece ter 
colaborado muito para isso, já que nem sempre havia um aproveitamento satisfatório das oportunidades de diálogo e convivência, e o contato sexual ficou reduzido para os participantes. Em relação a isso, Bradt (2001) comenta que as tarefas e exigências da parentalidade podem reduzir as possibilidades de diálogo e intimidade. Entretanto, conforme Magalhães e Féres-Carneiro (2003), a noção de conjugalidade moderna considera a intimidade como condição essencial para uma relação fecunda.

Além disso, não se pode esquecer que a capacidade para a intimidade é característica da terceira individuação, indicando o cumprimento das tarefas desenvolvimentais da adolescência (Colarusso, 1990). Assim, embora os participantes já estivessem vivenciando algumas situações relativas à idade adulta jovem, como a parentalidade, situavam-se cronológica e emocionalmente na adolescência. Consequentemente, de acordo com Erikson (1998), poderiam não apresentar ainda as condições psíquicas necessárias para o estabelecimento de uma intimidade genuína, em função da falta de definição quanto à própria identidade.

Também não se pode desconsiderar que, para as jovens do presente estudo, o namorado havia sido o primeiro parceiro sexual. Então não haviam tido oportunidade de realizar as experimentações afetivas e sexuais que fazem parte da adolescência (Erikson, 1998; Papalia et al., 2006), em função da entrada precoce nessa esfera do mundo adulto, por meio da gravidez e de uma união afetiva. Dessa forma, a oscilação no equilíbrio individualidade-conjugalidade poderia ser decorrente ainda da falta de preparação para o casamento e a vida familiar, e, por consequência, da falta de clareza dos ajustamentos necessários para assegurar uma relação estável e harmônica, como o equilíbrio das necessidades pessoais e do parceiro no convívio diário (Martin, Martin \& Martin, 2001).

\section{CONSIDERAÇÕES FINAIS}

Os resultados do presente estudo revelaram a dificuldade dos participantes em equilibrar as dimensões individualidade e conjugalidade na relação de casal, desde a gestação até o segundo ano de vida da criança. Parece que, em função das inúmeras demandas práticas e emocionais colocadas aos jovens pela vivência simultânea da adolescência, da parentalidade e da relação de casal, eles acabaram se direcionando para o processo mais urgente, no caso, a parentalidade, uma vez que a presença do bebê mobilizou o cuidado e a responsabilidade. Com isso, as questões conjugais tenderam a ficar inicialmente em segundo plano, sendo retomadas a partir do crescimento do bebê. De qualquer forma, os resultados aqui encontrados foram muito semelhantes aos encontrados entre casais adultos, o que indica que a idade dos cônjuges per se pode não explicar a complexidade deste equilíbrio entre as dimensões individualidade e conjugalidade na transição para a parentalidade.

Os resultados desse estudo contribuem para a elaboração de intervenções que atendam às necessidades de adolescentes nesse momento do ciclo de vida. Seria importante a criação de programas comunitários com jovens casais grávidos, tendo em vista as inúmeras dificuldades que poderão enfrentar em função do início simultâneo da vida conjugal e da parentalidade, somadas à vivência da adolescência. Estes grupos poderiam se estender para além do nascimento da criança, enfatizando os aspectos e as demandas emocionais envolvidas na relação de casal nesse período. Pensa-se que tais intervenções teriam um importante valor terapêutico, pois auxiliariam os adolescentes no enfrentamento destas situações, facilitando uma convivência conjugal mais harmoniosa e satisfatória.

\section{REFERÊNCIAS}

Aberastury, A. (1981). O adolescente e a liberdade. (S. M. G. Ballve, Trad.). Em A. Aberastury \& M. Knobel (Orgs.), Adolescência normal: um enfoque psicanalítico $\left(10^{\mathrm{a}} \mathrm{ed}\right.$., pp. 13-23). Porto Alegre: Artes Médicas. (Original publicado em 1970)

Bardin, L. (1977). Análise de conteúdo. Lisboa: Edições70.

Bradt, J. O. (2001). Tornando-se pais: famílias com filhos pequenos. Em B. Carter \& M. McGoldrick (Orgs.), As mudanças no ciclo de vida familiar: uma estrutura para a terapia familiar (M. A. V. Veronese, Trad., 2a ed., pp. 206222). Porto Alegre: Artes Médicas. (Original publicado em 1989)

Braz, M. P., Dessen, M. A. \& Silva, N. L. P. (2005). Relações conjugais e parentais: uma comparação entre famílias de classes sociais baixa e média. Psicologia, Reflexão $e$ Crítica, 18(2), 151-161.

Colarusso, C. A. (1990). The third individuation: The effect of biological parenthood on separation-individuation processes in adulthood. Psychoanalitical Study of the Child, 45, 179-194.

Correa, C. N. (2001). A transição do casal para a parentalidade. Dissertação de Mestrado não publicada, Programa de Pós-Graduação em Psicologia do Desenvolvimento, Universidade Federal do Rio Grande do Sul, Porto Alegre.

Costa, G. P. \& Katz, G. (1992). Dinâmica das relações conjugais. Porto Alegre: Artes Médicas. 
Curran, M., Hazen, N., Jacobvitz, D. \& Feldman, A. (2005). Representations of early family relationships predict marital maintenance during the transition to parenthood. Journal of Family Psychology, 19(2), 189-197.

Dias, M. de V. (2000). A construção do casal: um estudo sobre as relações conjugais contemporâneas. [resumo] Tese de Doutorado não publicada, Programa de Pós-Graduação em Psicologia Clínica, Pontifícia Universidade Católica do Rio de Janeiro, Rio de Janeiro, Brasil. Recuperado em 11 jan. 2005: http://www.dbd.puc-rio.br

Erikson, E. H. (1998). O ciclo de vida completo. (M. A. V. Veronese, Trad.) Porto Alegre: Artes Médicas. (Original publicado em 1997)

Falcke, D., Diehl, J. A. \& Wagner, A. (2002). Satisfação conjugal na atualidade. Em A. Wagner (Org.), Família em cena: tramas, dramas e transformações (pp. 172-188). Petrópolis: Vozes.

Féres-Carneiro, T. (1998). Casamento contemporâneo: o difícil convívio da individualidade com a conjugalidade. Psicologia, Reflexão e Crítica, 11(2), 379-394.

Féres-Carneiro, T. (2001). Casamento contemporâneo: construção da identidade conjugal. Em T. Féres-Carneiro (Org.), Casamento e família: do social à clínica (pp. 6780). Rio de Janeiro: Nau Editora.

Féres-Carneiro, T. \& Magalhães, A. S. (2000). Retorno da conjugalidade sobre a subjetividade dos parceiros: uma questão para a clínica psicanalítica do casal. Recuperado em 15 jan. 2005: Disponível http://www.geocities.com/hotsprings/villa/3170/CarneiroM agalhaes.htm

GIDEP - Grupo de Pesquisa em Infância, Desenvolvimento e Psicopatologia/UFRGS (1998a). Entrevista de contato inicial. Instrumento não publicado.

GIDEP - Grupo de Pesquisa em Infância, Desenvolvimento e Psicopatologia/UFRGS (1998b). Termo de Consentimento Livre e Esclarecido. Instrumento não publicado.

GIDEP - Grupo de Pesquisa em Infância, Desenvolvimento e Psicopatologia/UFRGS (1998c). Entrevista de dados demográficos do casal. Instrumento não publicado.

GIDEP - Grupo de Pesquisa em Infância, Desenvolvimento e Psicopatologia/UFRGS (1998d). Narrativa conjunta sobre a história do casal. Instrumento não publicado.

GIDEP - Grupo de Pesquisa em Infância, Desenvolvimento e Psicopatologia/UFRGS (1999). Entrevista com o casal sobre a experiência da parentalidade - terceiro mês do bebê. Instrumento não publicado.

GIDEP - Grupo de Pesquisa em Infância, Desenvolvimento e Psicopatologia/UFRGS (2000). Entrevista com o casal sobre a experiência da parentalidade - primeiro ano do bebê. Instrumento não publicado.
GIDEP - Grupo de Pesquisa em Infância, Desenvolvimento e Psicopatologia/UFRGS (2001). Entrevista com o pai/mãe sobre o desenvolvimento do bebê - segundo ano do bebê. Instrumento não publicado.

Heilborn, M. L. (1995). O que faz um casal, casal? Conjugalidade, igualitarismo e identidade sexual em camadas médias urbanas. Em I. Ribeiro \& A. C. T. Ribeiro (Orgs.), Família em processos contemporâneos: inovações culturais na sociedade brasileira: Vol.10, Coleção Seminários Especiais, Centro João XXIII (pp. 91-106). São Paulo: Loyola.

Laville, C. \& Dionne, J. (1999). A construção do saber: manual de metodologia de pesquisa em Ciências Humanas. (H. Monteiro \& F. Settineri, Trads.). Porto Alegre: Artes Médicas. (Original publicado em 1997)

Lopes, R. de C. S., Menezes, C. C., Santos, G. P. dos \& Piccinini, C. A. (2006). Ritual de casamento e planejamento do primeiro filho. Psicologia em Estudo, 11(1), 55-61.

Magalhães, A. S. \& Feres-Carneiro, T. (2003). Conjugalidade e subjetividades contemporâneas: o parceiro como instrumento de legitimação do "eu". Trabalho apresentado no Segundo Encontro Mundial dos Estados Gerais da Psicanálise, Rio de Janeiro. Recuperado em 11 jan. 2005: http://www.estadosgerais.org/mundial.rj

Martin, P. D., Martin, D. \& Martin, M. (2001). Adolescent premarital sexual activity, cohabitation, and attitudes toward marriage. Adolescence, 36(143), 601-609.

Papalia, D. E., Olds. S. W. \& Feldman, R. (2006). Desenvolvimento humano. (D. Bueno, Trad., $8^{\mathrm{a}} \mathrm{ed}$.). Porto Alegre: Artes Médicas. (Original publicado em 2001)

Piccinini, C. A.; Tudge, J.; Lopes, R. S. \& Sperb, T. M. (1998). Estudo longitudinal de Porto Alegre: da gestação à escola. Instituto de Psicologia, UFRGS. Projeto de pesquisa não publicado.

Stake, R. E. (1994). Case studies. Em N. Denzin \& Y. Lincoln (Org.), Handbook of Qualitative Research (pp. 236-247). Londres: Sage.

Walsh, F. (2002). Casais saudáveis e casais disfuncionais: qual a diferença? (L. Kahl \& G. Menegoz, Trads.). Em M. Andolfi (Org.), A crise do casal - uma perspectiva sistêmico-relacional (pp. 13-28). Porto Alegre: Artes Médicas. (Original publicado em 2001).

Recebido em 26/04/07 Aceito em 27/05/08

Endereço para correspondência : $\quad$ Daniela Centenaro Levandowski. UFCSPA - Rua Sarmento Leite, 245, sala 207, CEP 90050170, Porto Alegre-RS, Brasil.E-mail: d.cl@terra.com.br 
